\title{
Improvement of Environmental Stability of the Antireflective Coating by PEG Modified $\mathrm{SiO}_{2}$ Sol
}

\author{
Jianbin Feng, Jichen Huang \\ College of Science, Shanghai University of Science and Technology, Shanghai, China \\ Email: f2565452583@yahoo.com
}

How to cite this paper: Feng, J.B. and Huang, J.C. (2017) Improvement of Environmental Stability of the Antireflective Coating by PEG Modified $\mathrm{SiO}_{2}$ Sol. Journal of Materials Science and Chemical Engineering, 5, 1-8.

https://doi.org/10.4236/msce.2017.55001

Received: April 20, 2017

Accepted: May 23, 2017

Published: May 26, 2017

Copyright $\odot 2017$ by authors and Scientific Research Publishing Inc. This work is licensed under the Creative Commons Attribution International License (CC BY 4.0).

http://creativecommons.org/licenses/by/4.0/

\begin{abstract}
As the antireflective coating prepared by sol-gel method had poor environmental stability, sol-modified method was used to improve its performance. The alkaline silica sol was prepared in ethanol solvent by using tetraethyl orthosilicate (TEOS) as precursors and aqueous ammonia as catalyst (content 28\%). Polyethylene glycol (PEG200) was used to modify the silica sol and the antireflective (AR) coating was prepared by dip-coating from the modified sol. The transmittance, composition, refractive index, and hydrophobicity of AR coating were discussed by combining the spectrophotometer, FTIR, Coating Wizard 32 coating design software, optical microscopy imaging system and JC2000A static droplet contact angle measurement software. Finally, the environmental stability of the AR coating was tested. The results showed that AR coating transmittance decreased by less than $0.1 \%$ after UV light for 20 hours and its transmittance decreased by about $0.57 \%$ in the humid environment for 2 months. Resistance to environmental stability has been improved.
\end{abstract}

\section{Keywords}

Environmental Stability, Hydrophobicity, AR Coating, Sol-Gel

\section{Introduction}

Sol-gel technology has attracted wide attention in the field of nanoporous materials because of its simple process, high purity of products, normal temperature and pressure operation and so on [1]. And it has shown its strong use value in the field of coating preparation [2] [3]. This kind of coating is a product of silica sol prepared using Stober method [4], in which silicon alkoxides hydrolyze and condense in alcohol solvents in the presence of water and a catalyst (e.g., $\mathrm{NH}_{3}$ ). The nanoporous properties of this AR coating impart a higher transmittance and laser damage threshold while limiting the environmental stability of the coating [5] [6]. Therefore, the appropriate treatment must be carried out before the use 
of the coating, so that it has a certain degree of environmental stability in order to cope with the needs of the environment.

At present, the modification method for the AR coating is mainly divided into two kinds of sol-modification [7]-[18] and coating surface treatment [19] [20] [21]. Coating surface treatment is through the coating surface effective group grafting and other means to change the performance of the coating surface and thus improve the coating's environmental stability. Sol-modification is the introduction of modifier in the aging stage of sol by adjusting the microstructure and chemical composition of $\mathrm{SiO}_{2}$ particles in the sol, so as to effectively resist the pollution of the external environment. Li xiaoguang et al. [22] [23] [24] obtained sol-gel silica coatings with high laser damage threshold and the stability in vacuum with organic contaminants by adding PEG in the sol. However, the stability of the environment for humid environments and UV light has not been reported. In this paper, by adding PEG200 in the sol to adjust the sol structure [25], we explored the environment stability of the AR coating combined with the change in transmittance. The environmental stability of the AR coatings in humid environments and UV light environments has been improved.

\section{Experimental Details}

\subsection{Materials}

Tetraethyl orthosilicate (TEOS), anhydrous ethanol (EtOH, 99.9\%), aqueous ammonia (28\%) and Polyethylene glycol (PEG200) were purchased from Sinopharm Chemical Reagent Co. Ltd. All chemicals agents were directly used without further purification.

\subsection{Preparation of PEG-Silica Sol}

The base-catalyzed silica sol was prepared using the Stober method [4]. A solution of aqueous ammonia and the half of the prescribed amount of EtOH was first added into a solution consisting of TEOS and the other half of the prescribed amount of EtOH under stirring. The final molar ratio of the base- catalyzed silica sol was TEOS: EtOH: $\mathrm{NH}_{3} \cdot \mathrm{H}_{2} \mathrm{O}=1: 38: 2.45$. Then, the resultant sol was sealed in a glass container and stirred for $2 \mathrm{~h}$ at $25^{\circ} \mathrm{C}$. In order to obtain silica particles suitable for coating, the resultant sol was aged in an appropriate environment with $20^{\circ} \mathrm{C}-25^{\circ} \mathrm{C}$ and relative humidity (RH) lower than $50 \%$ for 4 days, followed by the slow addition of The molar ratio of 0.1 (PEG200/TEOS $=$ 0.1 ), stirring for 1 hour to continue aging for 3 days. In the end, it had to be refluxed for $24 \mathrm{~h}$ to remove the ammonia at $80^{\circ} \mathrm{C}$ and stored to use (Figure 1).

\subsection{Coating Preparation}

The sol was deposited on the well-cleaned BK7 substrates and silicon wafers (using for FTIR) by dip-coating apparatus (CHEMAT Dip Master-200) with a fixed withdraw rate $(0-12 \mathrm{inch} / \mathrm{min})$ in a super clean room with the temperature of $25^{\circ} \mathrm{C}$, and relative humidity $(\mathrm{RH})$ was less than $50 \%$. The substrate was placed in a muffle stove at $100^{\circ} \mathrm{C}$ heat treatment for $2 \mathrm{~h}$ to get the final sample. 


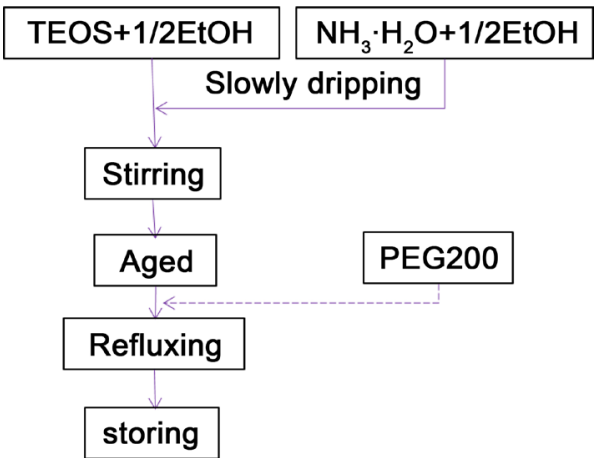

Figure 1. Preparation process of PEG200 modified $\mathrm{SiO}_{2}$ sol.

The samples were prepared and referred as: unmodified silica coating (Base$\mathrm{SiO}_{2}$ ) and PEG modified coating $\left(\mathrm{PEG}-\mathrm{SiO}_{2}\right)$, respectively.

\subsection{Characterization}

The transmittance and reflection spectra of silica AR coatings were measured with an UV-vis-NIR spectrophotometer (JASCOV-570). The refractive index of silica AR coatings was determined using Coating Wizard 32 (SCI, Scientific Computing International) software. The chemical composition of silica AR coatings was obtained using Fourier transform infrared (FTIR) spectrometer (BRUKER TENSOR-27). The water contact angle (WCA) of silica AR coatings was measured using an optical contact-angle meter system (home-made). Resistance to environmental stability test is carried out, including the following simulated environment: 1 ) in the closed dryer to store distilled water to create a humid environment ( $\mathrm{RH}>90 \%$ ); 2 ) in the UV irradiation box (power $1 \mathrm{kw}$ ) to achieve UV radiation environment.

\section{Results and Discussion}

\subsection{Optical Properties of the Coating}

Figure 2 shows the transmittance (a) and refractive index (b) of AR coating of Base- $\mathrm{SiO}_{2}$ and $\mathrm{PEG}-\mathrm{SiO}_{2}$. As can be seen from Figure 2(a), the transmittance of PEG-SiO ${ }_{2}$ is more than $99.8 \%$, which is more excellent than $\mathrm{Base}_{-} \mathrm{SiO}_{2}$. It is also found that the refractive index (Figure 2(b)) of PEG-SiO${ }_{2}$ is closer to 1.22 , so that the coating has more excellent optical performance.

\subsection{Chemical Analysis by FTIR Spectroscopy}

Figure 3 shows FTIR spectrum of AR coatingsofBase- $\mathrm{SiO}_{2}$ and $\mathrm{PEG}-\mathrm{SiO}_{2}$. Several characteristic absorption bands were observed in the range between 750 and $4000 \mathrm{~cm}^{-1}$. The absorption band observed around $2981 \mathrm{~cm}^{-1}$ is due to stretching and bending of $\mathrm{C}-\mathrm{H}$ bonds. The most intense absorption peak centered at 1085 $\mathrm{cm}^{-1}$ is an asymmetry stretching vibration of Si-O-Si bonds and the peak observed at $800 \mathrm{~cm}^{-1}$ is due to a symmetric stretching vibration of Si-O-Si bonds. The peak at $960 \mathrm{~cm}^{-1}$ is attributed to the $\mathrm{Si}-\mathrm{OH}$ groups and a shoulder around $1166 \mathrm{~cm}^{-1}$ is related to stretching of Si-O-groups. It can be seen from the figure 

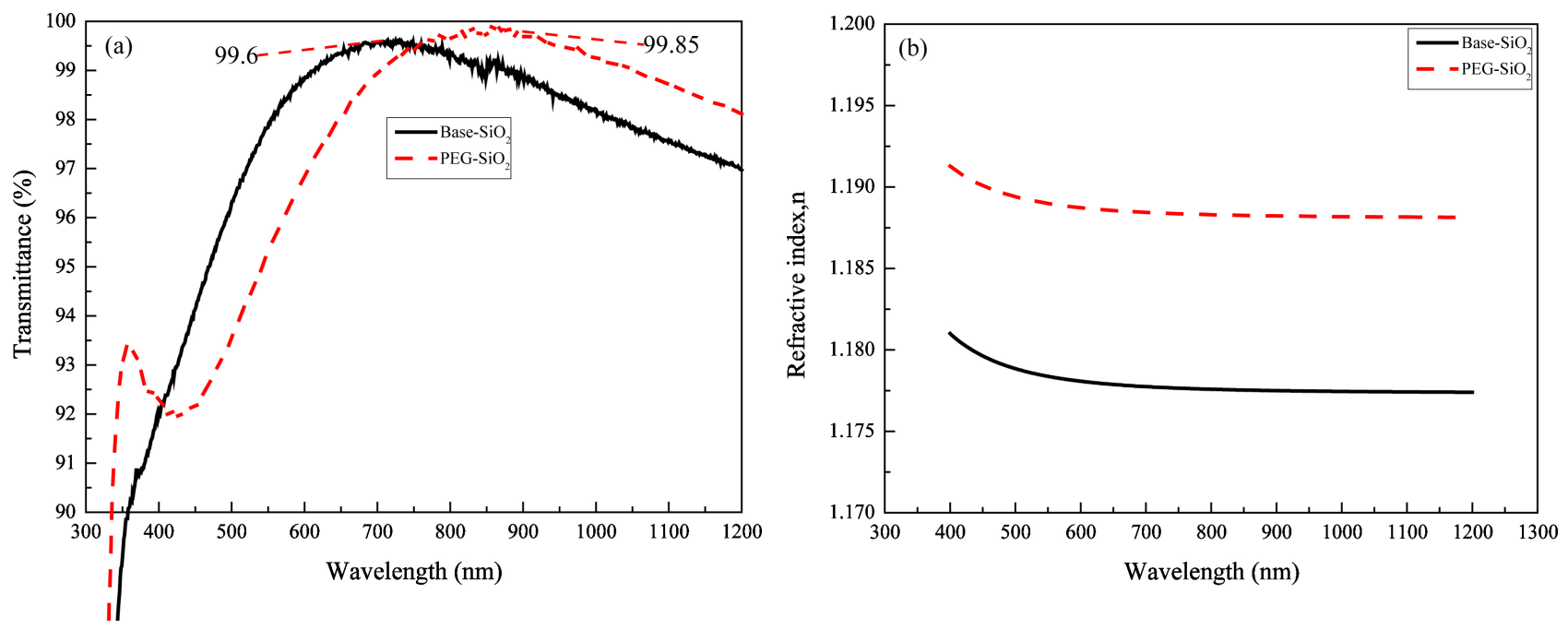

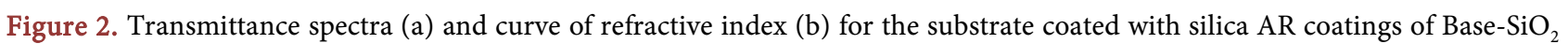
and PEG-SiO .

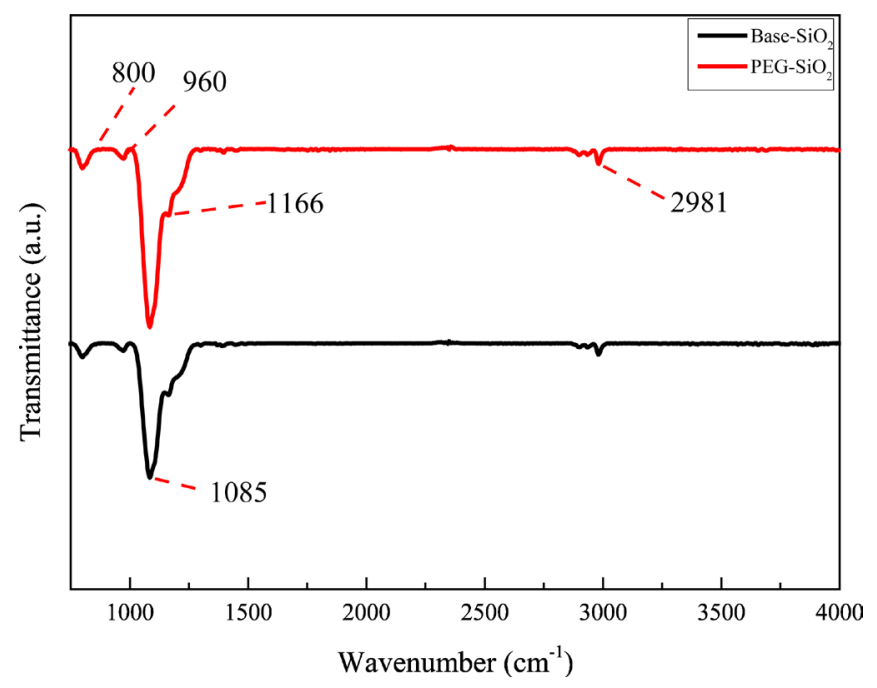

Figure 3. FTIR spectrum of AR coatingsofBase- $\mathrm{SiO}_{2}$ and $\mathrm{PEG}-\mathrm{SiO}_{2}$.

that there is no significant difference between the two coatings. Because the PEG200 does not contain special functional groups or its content is less (has been decomposed), no obvious absorption peak appears in the FTIR.

\subsection{Analysis of Water Contact Angle}

Figure 4 is the picture of water contact angle of AR coatings of $\mathrm{Base}_{-} \mathrm{SiO}_{2}$ (a) and $\mathrm{PEG}-\mathrm{SiO}_{2}$ (b). It can be seen from the figure that the water contact angle between $\mathrm{Base}-\mathrm{SiO}_{2}\left(49.5^{\circ}\right)$ andPEG- $\mathrm{SiO}_{2}\left(54^{\circ}\right)$ is almost the same. This is because PEG200 in the sol is to control the growth of sol particles [25] and does not introduce hydrophobic functional groups, the water contact angle does not change much (only $5^{\circ}$ ).

\subsection{The Environmental Stability of UV Light for PEG-SiO}

Transmittance change spectra of AR coatings of $\mathrm{Base}^{-\mathrm{SiO}_{2}}$ (a) and PEG-SiO${ }_{2}$ (b) 


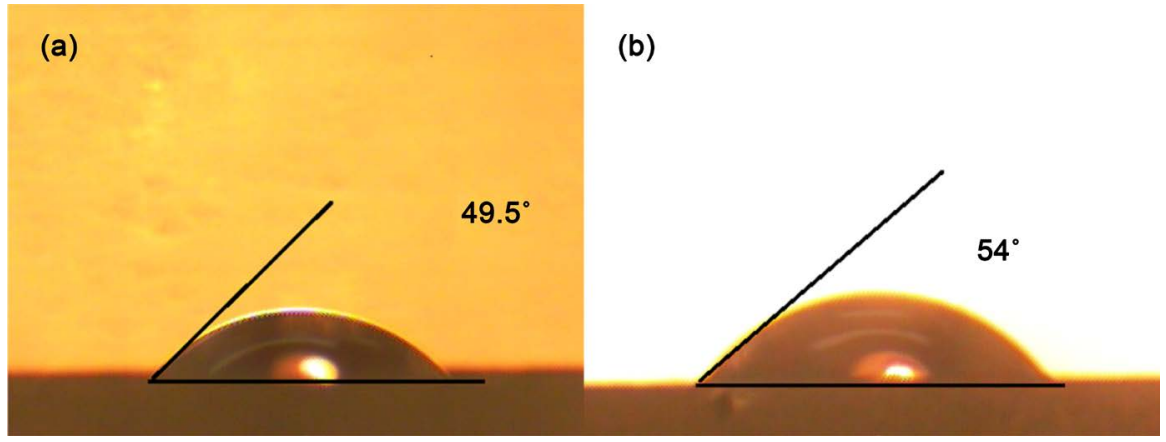

Figure 4. Picture of water contact angle of $\mathrm{AR}$ coatings of $\mathrm{Base}_{-} \mathrm{SiO}_{2}$ (a) and $\mathrm{PEG}-\mathrm{SiO}_{2}$ (b).
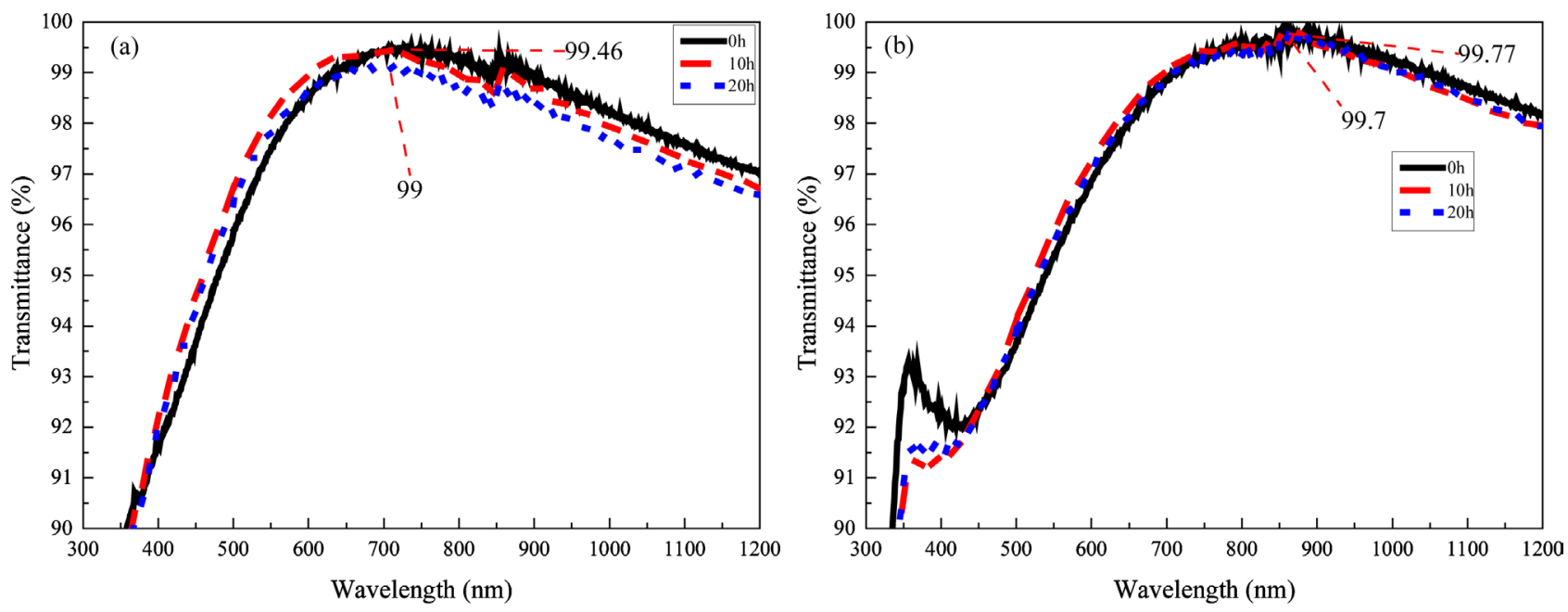

Figure 5. Transmittance change spectra of $\mathrm{Base}_{-} \mathrm{SiO}_{2}$ (a) and PEG-SiO${ }_{2}$ (b) in the UV light environment for $20 \mathrm{~h}$.

in the UV light environment for $20 \mathrm{~h}$ are shown in Figure 5. Base- $\mathrm{SiO}_{2}$ and PEG- $\mathrm{SiO}_{2}$ were put in UV irradiation box (power $1 \mathrm{kw}$ ) to achieve UV light environment. After 20 hours of UV light, the transmittance of $\mathrm{Base}_{-} \mathrm{SiO}_{2}$ decreases greater than $0.45 \%$, while the transmittance of $\mathrm{PEG}-\mathrm{SiO}_{2}$ decreases less than $0.1 \%$.

\subsection{The Environmental Stability of Humid Environment for PEG-SiO}

Figure 6 shows Transmittance change spectra of $\mathrm{Base}_{-} \mathrm{SiO}_{2}$ (a) and PEG-SiO${ }_{2}$ (b) in a humid environment for 2 months. Base-SiO $\mathrm{S}_{2}$ and $\mathrm{PEG}-\mathrm{SiO}_{2}$ were put in a closed drier with deionized water $(\mathrm{RH}>90 \%)$ to achieve humid environment. After 2 months of humid environment, the transmittance of $\mathrm{Base}_{-} \mathrm{SiO}_{2}$ decreases greater than $1.47 \%$, while the transmittance of PEG-SiO${ }_{2}$ decreases less than $0.57 \%$. Significantly, the environmental stability of AR coating is improved on the humid environment.

\section{Conclusion}

In this study, alkaline silica sol was prepared by sol-gel method and modified by adding appropriate amount of PEG200 to alkaline silica sol to obtain the cor- 

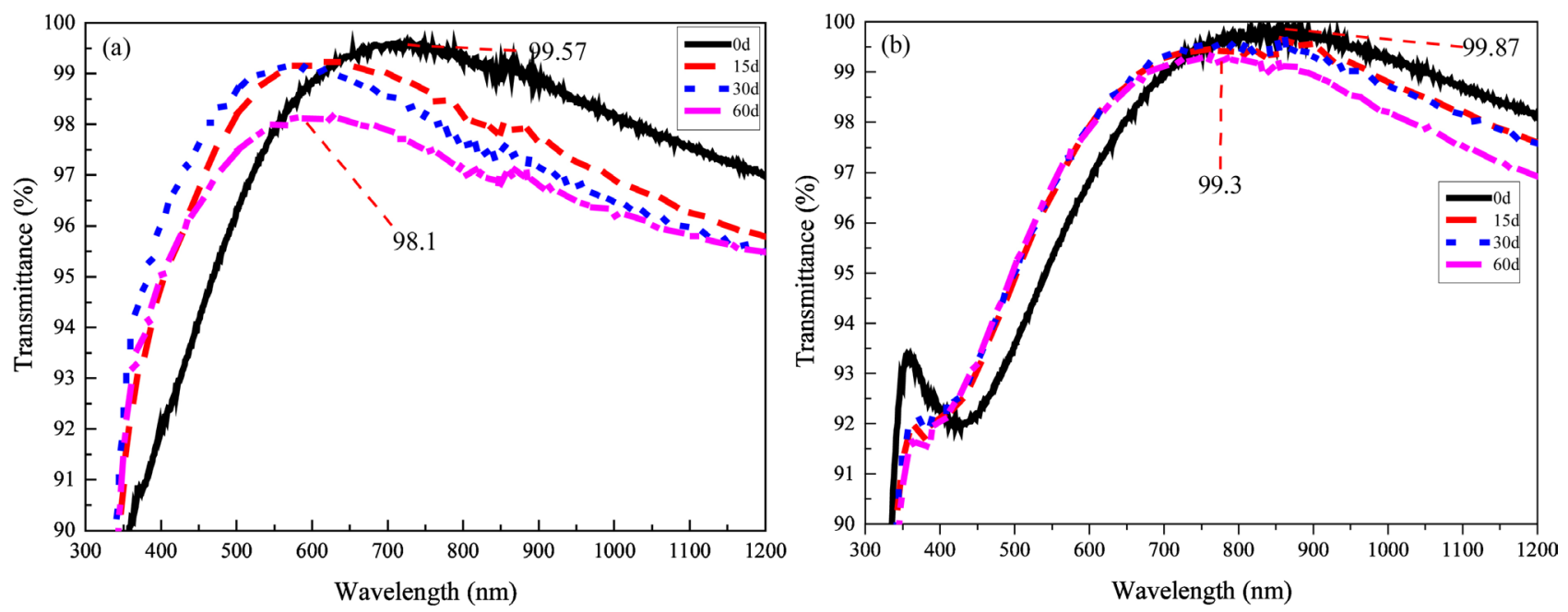

Figure 6. Transmittance change spectra of $\mathrm{Base}_{-} \mathrm{SiO}_{2}$ (a) and $\mathrm{PEG}-\mathrm{SiO}_{2}$ (b) in a humid environment for 2 months.

responding modified sol. The changes of transmittance, refractive index, FTIR and water contact angle of AR coatings of $\mathrm{Base}-\mathrm{SiO}_{2}$ and PEG-SiO${ }_{2}$ were discussed. The coating of the corresponding modified sol has a better transmittance than that of the unmodified sol. And finally, good environmental stability of AR coating is obtained in the UV light and humid environment.

\section{References}

[1] Brinker, C.J. and Scherer, G.W. (2013) Sol-Gel Science: The Physics and Chemistry of Sol-Gel Processing. Academic Press, Cambridge, MA.

[2] Lin, Y. and He, J. (2014) Recent Progress in Antireflection and Self-Cleaning Technology-From Surface Engineering to Functional Surfaces. Progress in Materials Science, 61, 94-143.

[3] Aegerter, M.A. and Mennig, M. (2013) Sol-Gel Technologies for Glass Producers and Users. Springer Science \& Business Media, Berlin.

[4] Stöber, W., Fink, A. and Bohn, E. (1968) Controlled Growth of Monodisperse Silica Spheres in the Micron Size Range. Journal of Colloid and Interface Science, 26, 62-69.

[5] Wang, X. and Shen, J. (2011) A Review of Contamination-Resistant Antireflective Sol-Gel Coatings. Journal of Sol-Gel Science and Technology, 61, 206-212. https://doi.org/10.1007/s10971-011-2615-4

[6] Shao, J.-D., Dai, Y.-P. and Xu, Q. (2011) Progress on the Optical Materials and Components for the High Power Laser System in China. Proceedings of the SPIE, 8206, Article ID: 820605. https://doi.org/10.1117/12.911108

[7] Yuan, Y., Yan, G., Liu, S., Lu, X. and Hong, R. (2016) Hydrophobic, Ultra-Low Refractive Index Coatings Prepared by Sol-Gel Process. Materials Letters, 184, $305-$ 307.

[8] Tao, C., Yan, H., Yuan, X., Yin, Q., Zhu, J., Ni, W., Yan, L. and Zhang, L. (2016) Detailed Analysis and Formation Mechanism of Superhydrophobic Antireflective Coatings with Adjustable Refractive Index from Trimethylsilanized Silica Nanoparticles. Journal of Sol-Gel Science and Technology, 80, 10-18. https://doi.org/10.1007/s10971-016-4056-6

[9] Zhang, Q., Wei, Y., Yang, W., Hui, H., Deng, X., Wang, J., Xu, Q. and Shen, J. 
(2015) Improvement on Contamination Resistance to Volatile Organics and Moisture of Sol-Gel Silica Antireflective Coating for $351 \mathrm{~nm}$ Laser System by Structural Modulation with Fluorinated Compounds. RSC Advances, 5, 4529-4536. https://doi.org/10.1039/C4RA10028J

[10] Zhang, X., Zhuang, M., Miao, X., Su, W., Lin, M., Lin, L., Ye, L., Yan, L., Yang, W. and Jiang, B. (2014) Environment-Resistant Fluoro-Containing Antireflective Coatings for High-Powered Laser Systems. RSC Advances, 4, 48872-48875. https://doi.org/10.1039/C4RA05449K

[11] Zhang, X., Zheng, F., Ye, L., Xiong, P., Yan, L., Yang, W. and Jiang, B. (2014) A One-Pot Sol-Gel Process to Prepare a Superhydrophobic and Environment-Resistant Thin Coating from ORMOSIL Nanoparticles. RSC Advances, 4, 9838-9841. https://doi.org/10.1039/c3ra47185c

[12] Sun, J., Zhang, Q., Ding, R., Lv, H., Yan, H., Yuan, X. and Xu, Y. (2014) Contamination-Resistant Silica Antireflective Coating with Closed Ordered Mesopores. Physical Chemistry Chemical Physics, 16, 16684-16693. https://doi.org/10.1039/C4CP01032A

[13] Zhang, Q., Zhou, L., Yang, W., Hui, H., Wang, J. and Xu, Q. (2014) Sol-Gel Preparation of a Silica Antireflective Coating with Enhanced Hydrophobicity and Optical Stability in Vacuum. Chinese Optics Letters, 12, 071601-71604. https://doi.org/10.3788/COL201412.071601

[14] Liu, Y., Shen, J., Zhou, B., Wu, G. and Zhang, Z. (2013) Effect of Hydrophobicity on the Stability of Sol-Gel Silica Coatings in Vacuum and Their Laser Damage Threshold. Journal of Sol-Gel Science and Technology, 68, 81-87. https://doi.org/10.1007/s10971-013-3137-z

[15] Zhang, Y., Zhang, X., Ye, H., Xiao, B., Yan, L. and Jiang, B. (2012) A Simple Route to Prepare Crack-Free Thick Antireflective Silica Coatings with Improved Antireflective Stability. Materials Letters, 69, 86-88.

[16] Zhang, X.-X., Xia, B.-B., Ye, H.-P., Zhang, Y.-L., Xiao, B., Yan, L.-H., Lv, H.-B. and Jiang, B. (2012) One-Step Sol-Gel Preparation of PDMS-Silica ORMOSILs as Environment-Resistant and Crack-Free Thick Antireflective Coatings. Journal of Materials Chemistry, 22, 13132-13140. https://doi.org/10.1039/c2jm31005h

[17] Zhang, X., Zhang, Y., Ye, H., Xiao, B., Yan, L., Lv, H. and Jiang, B. (2011) Sol-Gel Preparation of Antireflective Coatings at $351 \mathrm{~nm}$ with Different Thickness and Improved Moisture-Resistance. Journal of Sol-Gel Science and Technology, 58, 340344. https://doi.org/10.1007/s10971-011-2398-7

[18] Xiao, B., Zhang, Y., Zhang, X., Lv, H., Yan, L. and Jiang, B. (2011) Focus on Moisture-Resistance and Hydrophobicity of $\mathrm{SiO}_{2}$ Antireflective Coating Improved by Poly(Isopropylene Oxide) Glycerolether. Journal of Sol-Gel Science and Technology, 60, 11-16. https://doi.org/10.1007/s10971-011-2544-2

[19] Yang, L., Xiang, X., Miao, X., Li, Z., Zhou, G., Yan, Z., Yuan, X., Zheng, W. and Zu, $X$. (2015) Influence of Outgassing Organic Contamination on the Transmittance and Laser-Induced Damage of $\mathrm{SiO}_{2}$ Sol-Gel Antireflection Coating. Optical Engineering, 54, 126101-126101. https://doi.org/10.1117/1.OE.54.12.126101

[20] Sun, J., Zhang, C., Zhang, C., Ding, R. and Xu, Y. (2014) Effect of Post-Treatment on Ordered Mesoporous Silica Antireflective Coating. RSC Advances, 4, 5087350881. https://doi.org/10.1039/C4RA06788F

[21] Ellison, M.J., Marshall, K.L., Culakova, Z., Ashe, B., Giacofei, C., Rigatti, A.L., Kessler, T.J., Schmid, A.W., Oliver, J.B. and Kozlov, A. (2007) Vapor-Phase-Deposited Organosilane Coatings as Hardening Agents for High-Peak-Power Laser Optics. Proceedings of the SPIE, 6674, Article ID: 667407. 
[22] Li, X., Gross, M., Oreb, B. and Shen, J. (2012) Increased Laser-Damage Resistance of Sol-Gel Silica Coating by Structure Modification. The Journal of Physical Chemistry C, 116, 18367-18371. https://doi.org/10.1021/jp307390u

[23] Li, X. and Shen, J. (2011) A Scratch-Resistant and Hydrophobic Broadband Antireflective Coating by Sol-Gel Method. Thin Solid Coatings, 519, 6236-6240.

[24] Li, X. and Shen, J. (2011) The Stability of Sol-Gel Silica Coatings in Vacuum with Organic Contaminants. Journal of Sol-Gel Science and Technology, 59, 539-545. https://doi.org/10.1007/s10971-011-2524-6

[25] Tian, H., Zhang, L., Xu, Y., Wu, D., Wu, Z.H., Lv, H. and Yuan, X.D. (2012) Comparison of Silica Anti-Reflective Coatings Obtained via a Sol-Gel Process in the Presence of PEG or PVP. Acta Physico-Chimica Sinica, 28, 1197-1205.

Submit or recommend next manuscript to SCIRP and we will provide best service for you:

Accepting pre-submission inquiries through Email, Facebook, LinkedIn, Twitter, etc. A wide selection of journals (inclusive of 9 subjects, more than 200 journals)

Providing 24-hour high-quality service

User-friendly online submission system

Fair and swift peer-review system

Efficient typesetting and proofreading procedure

Display of the result of downloads and visits, as well as the number of cited articles

Maximum dissemination of your research work

Submit your manuscript at: http://papersubmission.scirp.org/

Or contact msce@scirp.org 